\title{
PERAN PENYESUAIAN DIRI SEBAGAI MEDIATOR DARI PENGARUH RELIGIUSITAS TERHADAP KEBAHAGIAAN SANTRI PONDOK PESANTREN
}

\author{
Mutiara Subhiyah \\ Universitas Islam Indonesia, Yogyakarta, Indonesia \\ 16915023@students.uii.ac.id \\ Fuad Nashori* \\ Universitas Islam Indonesia, Yogyakarta, Indonesia \\ fuadnashori@uii.ac.id
}

\begin{abstract}
This study aimed to examine self-adaptation role as mediator in the correlation of religiosity and happiness. This study involves 204 new students from Islamic Boarding School X in Bekasi, West Java, Indonesia. This study used Oxford Happiness Questionnaire (OHQ) scale as developed by Hills and Argyle, Indonesian Psychological Measurement of Islamic Religiousness (IPMIR) developed by Abu-Raiya, et al and Student Adaptation to College Questionnaire (SACQ) by Baker and Siryk. The data were analyzed by means of exploratory factor analysis and process macro analysis using SPSS 20 software. The results of this study showed that religiosity positively affecting self-adaptation and happiness, and self-adaptation mediated the effects of religiosity on happiness. Thus, the hypothesis in this study was accepted.
\end{abstract}

Keywords; Happiness, Religiosity, Self-Adaptation, Islamic Boarding School

\footnotetext{
${ }^{*}$ Corresponding Author
} 


\section{PENDAHULUAN}

Kebahagiaan merupakan salah satu aspek yang penting pada kesehatan mental pelajar, termasuk para santri. Disebut penting karena pelajar yang merasa bahagia menunjukkan performa yang lebih baik di sekolah, jarang menunjukkan masalah pada kesehatan mental dan perilaku, serta memiliki hubungan sosial yang lebih kuat (Cleveland \& Sink, 2018). Kebahagiaan juga berperan penting dalam meningkatkan produktivitas, performa kerja, kesuksesan karir, juga kesehatan (Roessler \& Gloor, 2020).

Wawancara peneliti dengan pengurus asrama di Pondok Pesantren $X$ di Bekasi Jawa Barat yang berinisial $M$ dan A, usia 20 dan 21 tahun, menunjukkan bahwa pada tahun pertama tidak jarang ditemukan santri-santri yang kerap menangis dan menolak untuk mengikuti kegiatan pondok. Ketika orang tua datang menjenguk, mereka menangis memeluk ibunya dan meminta untuk ikut pulang. Pada kasus lain, santri di tahun pertama ini melarikan diri dari asrama sebelum kemudian diantar kembali oleh orangtuanya. Perilaku santri ini tidak hanya menimbulkan masalah pada akademiknya, namun juga pada hubungan sosial dengan temantemannya. Santri-santri ini kerap kali menyendiri dan tidak mau diajak temantemannya untuk bermain atau ke kantin. Ia selalu menangis di malam hari, sehingga membuat kesal temantemannya, dan membuat repot pengurus asrama karena mereka harus membujuk santri ini setiap kali ada kegiatan agar ini mau berpartisipasi.

Dari hasil wawancara peneliti dengan salah satu santri yang berinisial $\mathrm{H}$, santri lelaki bersusia 12 tahun, didapatkan bahwa semenjak masuk ke pondok pesantren ia merasa sedih karena harus berpisah dengan teman-teman di sekolah dasarnya. Ia merasa kesulitan untuk menjalin pertemanan baru dan merasa takut santri-santri lain tidak akan menyukainya. Hurlock (2002) menyatakan bahwa salah satu faktor paling penting pada kebahagiaan remaja adalah penerimaan, baik penerimaan diri sendiri maupun penerimaan atau dukungan sosial. Santri lain bercerita bahwa meskipun sudah berada di tahun ketiga, ia seringkali merasa sedih dan tidak bahagia. Ia selalu merindukan keluarganya dan kamar tidurnya yang nyaman. Ia mengikuti semua kegiatan pondok yang wajib tanpa semangat, dan menolak berpartisipasi pada kegiatan yang tidak wajib seperti perlombaan, ekstrakurikuler dan kegiatan bakti sosial. Perilaku apatis ini, menurut Nettle (Mundzir, 2014), adalah bentuk dari ketidakbahagiaan seseorang.

Kebahagiaan seseorang dapat dipengaruhi oleh beberapa hal di antaranya adalah gender atau seks, usia, pendidikan, kualitas pernikahan, kepuasan pekerjaan, kesehatan, serta agama atau religiusitas (Eddington \& Shuman, 2005). Seligman, Peterson, dan Lyuborsmisky (Arif, 2018) membagi faktor yang mempengaruhi kebahagiaan seseorang menjadi tiga, yaitu faktor genetik atau bawaan yang tidak bisa diubah seperti kepribadian, watak dan preferensi, faktor lingkungan yang berkaitan dengan situasi kehidupan yang berubah-ubah, dan faktor ketiga, yaitu bagaimana individu merespon atau menyesuaikan diri dengan lingkungannya. Dalam penelitian ini, 
peneliti mencoba mengkaji lebih dalam bagaimana peran religiusitas mempengaruhi kebahagiaan santri dan peran penyesuaian diri sebagai mediator di antara keduanya. Religiositas sendiri menurut Ancok dan Suroso (1994) dapat diartikan sebagai keyakinan, ritual, perilaku sosial, pengalaman keagamaan, dan pengetahuan yang terkait dengan yang transenden yang terorganisasi dalam agama tertentu, dalam penelitian ini adalah agama Islam.

Wulff (Baroun, 2006) menyatakan bahwa religiositas memiliki hubungan yang positif dengan kepuasan hidup, penyesuaian diri, kontrol diri, harga diri (self-esteem), kebahagiaan, kesehatan fisik dan mental, serta memiliki hubungan yang negatif dengan kecemasan secara umum, kecemasan akan kematian, neurotisme, depresi, dan impulsifitas. Penelitian-penelitian terdahulu telah menemukan bahwa religiositas memiliki hubungan yang signifikan dengan kebahagiaan individu, di mana individu yang religius mememiliki kesehatan mental dan fisik, kepuasan hidup, gaya hidup sehat dan kesejahteraan psikologis yang lebih tinggi dibandingkan individu non-religius (Mahudin, Noor, Dzulkifli, \& Janon, 2016; Abdel-Khalek, 2019; Graham \& Haidt, 2010). Hal ini dikarenakan agama tidak hanya memenuhi kebutuhan spiritual seseorang, tetapi juga kebutuhan sosialnya (Graham \& Haidt, 2010). Santri dengan religiositas yang tinggi memiliki kelapangdadaan dan kebermaknaan hidup yang lebih tinggi, serta karakter yang kuat seperti kebersyukuran, kebaikan, dan kejujuran (Nashori, 2011). Hal ini dikarenakan agama dapat memberikan santri perasaan hidup yang bermakna, sejahtera secara psikologis dan hubungan sosial yang kuat (Hossain \& Rizvi, 2017).

Dalam penelitiannya, Rusman (2019) menuliskan bahwa religiositas dapat mempengaruhi kebahagiaan seseorang tidak secara langsung melainkan dimediasi oleh beberapa faktor seperti kontrol diri, regulasi diri, kepuasan hidup, dan kemampuan individu untuk beradaptasi dengan kejadian-kejadian dalam hidupnya. Religiositas terbukti dapat mempengaruhi kemampuan penyesuaian dirinya (Nadzir \& Wulandari, 2013; Lesatari \& Indrawati, 2017). Dalam penelitian yang dilakukan oleh Pritaningrum dan Hendriani pada santri baru di pondok pesantren, di mana santri baru ini ada yang sebelumnya sekolah di Sekolah Menengah Pertama (SMP) dan Madrasah Tsnawiyah (MTs). Hasil penelitian memperlihatkan bahwa santri baru yang berasal dari SMP memiliki kemampuan menyesuaikan diri yang lebih rendah dibandingkan dengan santri baru yang sebelumnya sekolah di MTs. Hal ini dikarenakan santri baru lulusan MTs mendapatkan pelajaran agama yang lebih banyak dan beragam dibandingkan dengan lulusan SMP. Selain itu santri dari MTs juga lebih terbiasa dengan pelajaranpelajaran agama dari sekolah sebelumnya sehingga ia tidak memiliki kesulitan untuk mengikuti pelajaran di pondok. Penelitian Qomariyah (2019) menunjukkan bahwa santri yang memiliki religiositas tinggi memiliki kemampuan penyesuaian diri yang tinggi pula. Hal ini terlihat dalam bentuk aktif dalam kegiatan sekolah dan rajin mengikuti kegiatan ibadah bersama-sama seperti sholat berjamaah di masjid dan mengaji bersama. 
Menurut riset Rusman (2019), pengaruh dari religiositas terhadap kebahagiaan berjalan secara tidak langsung, melainkan dimediasi oleh kemampuan individu untuk beradaptasi dengan kejadian-kejadian dalam hidupnya. Penyesuaian diri berperan sebagai mediator dalam pengaruh religiositas terhadap kebahagiaan santri secara langsung. Penelitian-penelitian yang telah dilakukan menemukan bahwa penyesuaian diri pada remaja dapat mempengaruhi kebahagiaannya (Bazradshan dkk, 2018). Kemampuan menyesuaikan diri bagi santri merupakan hal yang sangat penting. Hal ini dikarenakan ia masuk ke lingkungan yang tidak familiar, tanpa adanya orangtua yang memenuhi segala kebutuhannya, di mana ia dituntut untuk mandiri dan bertanggung jawab terhadap dirinya, akademiknya dan sosialnya. Santri juga harus belajar menyesuaikan waktunya dengan kegiatan pondok yang padat, di mana ia hanya memiliki waktu terbatas untuk memenuhi kebutuhan pribadi seperti mandi, makan dan tidur (Rahma, 2016).

Santri di pondok pesantren memiliki latar belakang yang berbeda, baik daerah asal, bahasa, ekonomi, juga usia (Pritaningrum \& Hendriani, 2013). Dalam lingkungan dengan tingkat heterogenitas yang tinggi ini tidak jarang santri merasa kesulitan menyesuaikan diri karena takut tidak diterima oleh santri lainnya, padahal penerimaan pada remaja merupakan hal yang penting dalam kebahagiaannya (Hurlock, 2002).

Seperti yang sudah disampaikan sebelumnya bahwa tingkat religiositas seseorang dapat mempengaruhi kebahagiaan dirinya dengan penyesuaian diri sebagai mediator. Religiositas dapat mempengaruhi kemampuan menyesuaikan diri santri yang pada akhirnya dapat mempengaruhi kebahagiaanya. Penjelasan tentang hubungan antara variabel tersebut dapat dilihat pada bagan di bawah ini:

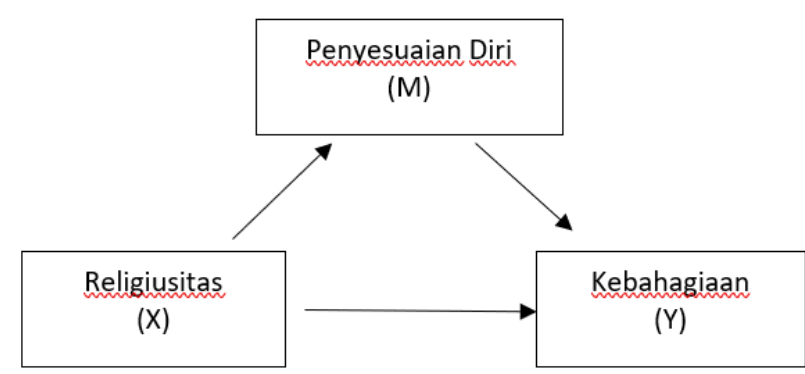

Bagan 1. Desain Analisis Penelitian

Berdasarkan pandangan di atas, maka hipotesis yang diajukan dalam penelitian ini adalah penyesuaian diri memiliki peran sebagai mediator dari pengaruh religiositas terhadap kebahagiaan santri. Hipotesis ini menjelaskan bahwa religiositas tidak secara langsung mempengaruhi kebahagiaan, namun diperantai oleh penyesuaian diri. Hipotesis itu dapat dijabarkan sebagai berikut: Penyesuaian diri memiliki peran sebagai mediator dari pengaruh religiositas terhadap kebahagiaan.

\section{METODE PENELITIAN}

Variabel dalam penelitian ini adalah kualitas penyesuaian diri sebagai variabel mediator, religiositas sebagai variabel prediktor dan kebahagiaan sebagai variabel kriteria.

\section{Partisipan Penelitian}

Partisipan penelitian dalam penelitian ini adalah 203 orang santri kelas VII Madrasah Tsanawiyah dan 47 orang santri kelas IX Madrasah Aliyah yang 
merupakan santri tahun pertama di pondok pesantren Attaqwa Bekasi Jawa Barat, berjenis kelamin laki-laki, dengan rentang usia 12-13 tahun dan 15-16 tahun.

Data dalam penelitian ini berasal dari data primer berupa kuesioner yang diberikan kepada santri baru di Pondok Pesantren Attaqwa Putera. Kuisioner disebarkan kepada partisipan dengan bantuan musyrif atau pengasuh asrama. Dari 250 kuisioner yang disebar hanya 223 yang dikumpulkan kepada peneliti, dan dari kuisioner yang berhasil dikumpulkan beberapa kuisioner diisi tidak lengkap oleh responden sehingga tidak peneliti masukkan dalam analisis data. Total data responden dalam penelitian ini adalah 204 orang.

\section{Instrumen Pengukuran}

Pengambilan data dalam penelitian ini menggunakan tiga skala yang telah dikembangkan oleh peneliti sebelumnya, yaitu skala kebahagiaan, skala religiositas, dan skala adaptasi siswa. Skala kebahagiaan dalam penelitian ini menggunakan Oxford Happiness Questionnaire (OHQ) yang pertama kali disusun oleh Argyle dan Crossland, kemudian diperbaiki oleh Hills dan Argyle pada tahun 2002 (Adeline, 2017). Skala kebahagiaan ini mengacu pada enam aspek kebahagiaan yang dikembangkan oleh Argyle dan Crossland (1987), yaitu life satisfaction, joy, self-esteem, calm, control, dan efficacy. Skala kebahagiaan ini terdiri atas 29 aitem, dengan pembagian 18 aitem favourable dan 11 aitem unfavourable. Alat ini telah diadaptasi ke dalam bahasa Indonesia oleh Rahmawati, Saragih dan Adeline (2016) dan ditemukan tingkat reliabilitas sebesar 0.83. Dari hasil analisis peneliti pada skala ini ditemukan nilai KMO 0.731 dan nilai Bartlett sebesar 0.000 yang membuatnya signifikan. Hasil analisis faktor ditemukan bahwa koefisien korelasi aitem total bergerak dari 0,403 hingga 0,644 dengan koefisien reliabilitas alpha $(\alpha) 0,792$ dan $0,669(>0.5)$ pada faktor 1 dan 2 yang membuatnya reliabel, sementara pada faktor ketiga didapatkan nilai Alpha Cronbach sebesar 0,174 yang membuat faktor ketiga ini tidak reliabel.

Religiositas subjek diukur dengan menggunakan skala IndonesianPsychological Measurement of Islamic Religiousness (I-PMIR) yang dikembangkan oleh Salsabila, dkk (2019). Skala ini merupakan adaptasi ke dalam Bahasa Indonesia dari skala Psychological Measure of Islamic Religiousness (PMIR) karya Abu-Raiya dkk (2008). Skala I-PMIR ini mengukur 5 aspek religiositas menurut Abu-Raiya dkk, yaitu belief, practices, ethical conduct - do, ethical conduct - don't, dan Islamic universality. Aitem dalam skala ini terdiri dari 41 aitem favourable dan 11 aitem unfavourable dengan total 52 aitem. Pada adaptasi skala I-PMIR oleh Salsabila, dkk (2019) ditemukan bahwa reliabilitas alat ini adalah sebesar 0.929. Dari hasil analisis peneliti pada skala ini ditemukan nilai 0.890 dan nilai Bartlett sebesar 0.000 yang membuatnya signifikan. Hasil analisis faktor ditemukan bahwa koefisien korelasi aitem total bergerak dari 0,9010,972 dengan koefisien reliabilitas alpha ( $\alpha$ ) 0,872 - 0,957 (>0.5) pada ketiga faktor membuatnya reliabel.

Adaptasi diri dalam penelitian ini diukur dengan menggunakan student adaptation to college questionnaire (SACQ) yang dikembangkan oleh Baker dan Siryk (1989). Skala ini dimaksudkan untuk mengukur kemampuan adaptasi 
mahasiswa di universitas, namun beberapa penelitian telah menggunakannya pada siswa usia sekolah menengah (Grama, 2018) dan pada santri di pondok pesantren (Afidah, 2017). Skala SACQ ini mengukur empat aspek penyesuaian diri pada siswa baru, yaitu academic adjustment yang terdiri dari motivation, application, performance, dan academic environment; kemudian social adjustment yang terdiri dari social adjustment in general, other people, nostalgia, dan social environment; personal emotional adjustment yang terdiri dari psychological dan physical; aspek terakhir yaitu goal commitment institutional attachment yang terdiri dari commitment in general, dan commitment in this college. Skala penyesuaian diri ini terdiri dari 67 aitem dengan pembagian 35 aitem favourable dan 32 aitem unfavourable.

Peneliti melakukan adaptasi pada alat ukur SACQ dikarenakan belum ada yang melakukan uji validitas dari alat ukur ini ke dalam bahasa Indonesia. Peneliti melakukan adaptasi ke dalam bahasa Indonesia dan disesuaikan dengan lokasi pengambilan data. Skala yang sudah diadaptasi kemudian dikonsultasikan kepada 3 orang psikolog alumni UII dan 2 orang psikolog yang bekerja di pondok pesantren tempat pengambilan data. Setelah dilakukan validitas isi dan disetujui, peneliti kemudian melakukan penyebaran skala penelitian melalui kuisioner kepada santri dengan bantuan pengurus asrama. Pengujian validitas dan reliabilitas skala ini dilakukan dengan menggunakan teknik uji coba terpakai, artinya instrument diuji dengan digunakan secara langsung kepada partisipan untuk mendapatkan data penelitian. Dari hasil analisis penelitian pada skala ini ditemukan nilai KMO pada skala penyesuaian diri sebesar 0.748 dan nilai Bartlett sebesar 0.000 yang membuatnya signifikan. Hasil analisis faktor ditemukan bahwa koefisien korelasi aitem total bergerak dari 0,324 - 0,777 dengan koefisien reliabilitas alpha $(\alpha) 0,673-0,915$ $(>0.5)$ pada ketiga faktor membuatnya reliabel.

\section{Metode Analisis Data}

Analisis data dalam penelitian ini menggunakan analisis PROCESS macro oleh Preacher dan Hayes (Hayes dkk, 2011) dengan teknik bootstrapping yang digunakan untuk mengambil keputusan terkait ada atau tidaknya pengarung tidak langsung dari variabel mediator salah satu model (Hayes et al, 2011). Analisis ini dilakukan menggunakan software SPSS 20 for windows dan PROCESS 3.5 for SPSS.

\section{HASIL}

Uji Hipotesis dalam penelitian ini menggunakan teknik analisis bootstraping yang digunakan untuk mengambil keputusan terkait ada atau tidaknya pengaruh tidak langsung dari variabel mediator salah satu model (Hayes et al, 2011). Berikut adalah gambaran dinamika hubungan ketika variabel dalam penelitian ini.

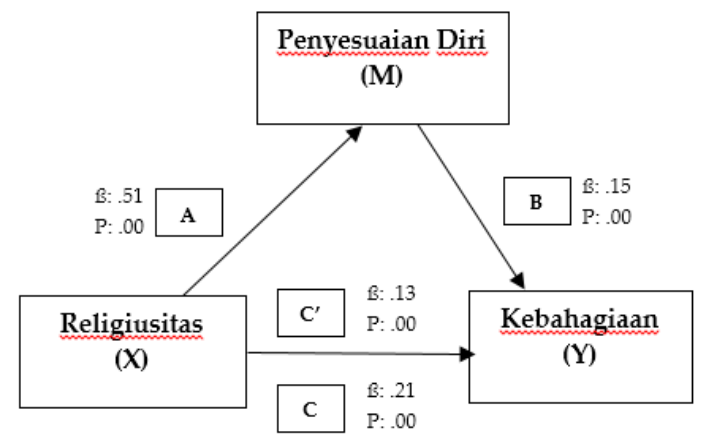

Bagan 2. Dinamika Hubungan Variabel-Variabel Penelitian 
Bagan di atas menunjukkan pengaruh langsung maupun tidak langsung dari variabel religiositas dan penyesuaian diri. Jalur A, yaitu pengaruh langsung religisiutas $(\mathrm{X})$ terhadap penyesuaian diri $(\mathrm{M})$ menunjukkan nilai koefisien sebesar 0,5186 dengan nilai signifikansi 0,000 atau $p<0,05$. Berarti, hubungan religiositas ke penyesuaian diri memiliki pengaruh yang signifikan. Jalur C menunjukkan pengaruh langsung religiositas $(X)$ terhadap kebahagiaan $(Y)$ mendapatkan koefisien sebesar 0,2164 dan signikansi pada taraf 0,000 atau $\mathrm{p}<0,05$. Hal ini menunjukkan bahwa religiositas memiliki pengaruh langsung terhadap kebahagiaan. Pada jalur B yaitu efek langsung penyesuaian diri $(\mathrm{M})$ terhadap kebahagiaan (Y) memiliki koefisien sebesar 0,1532 dan signifikansi sebesar 0,000 atau $p<0,05$. Berarti, efek langsung penyesuaian diri dapat mempengaruhi kebahagiaan secara signifikan. Terakhir jalur $C^{\prime}$ menunjukkan hubungan tidak langsung dari religiositas (X) terhadap kebahagiaan (Y) dengan dimediasi penyesuaian diri (M), didapatkan koefisien sebesar 0,2164 dan signikansi pada taraf 0,000 atau sig<0,05. Hal ini menunjukkan bahwa religiositas memiliki pengaruh tidak langsung terhadap kebahagiaan dengan dimediasi penyesuaian diri. Dengan kata lain, penyesuaian diri memiliki peran sebagai mediator dari pengaruh religiositas terhadap kebahagiaan.

Selanjutnya peneliti melakukan uji bootsrap untuk melihat apakah peran penyesuaian diri sebagai mediator merupakan mediasi penuh (full mediation) atau mediasi parsial (partial mediation). Mediasi parsial (partial mediation) terjadi ketika pengaruh dari religiositas terhadap kebahagiaan menurun namun tidak sampai nol ketika penyesuaian diri dihilangkan, sementara mediasi sempurna (perfect mediation) terjadi ketika variabel bebas tidak menunjukkan pengaruh terhadap variabel bebas ketika veriabel mediator dikontrol (Baron \& Kenny, 1986).

Hasil analisis bootstrap menunjukkan bahwa nilai koefisien indirect sebesar 0,0794 dari religiositas (X) ke kebahagiaan (Y). Interval kepercayaan (Confidence Interval / CI) dari hasil bootstrap tertulis BootLLCI (lower level for $C I)=0,0460$ dan BootULCI (Upper level for $C I)=0,0111$. Hal ini menunjukkan bahwa rentang BootLLCI dan BootULCI itu tidak sampai nol (0). Begitu pula pada pengaruh tidak langsung yang terstandar, didapatkan nilai BootLLCI = 0,0955 dan BootULCI $=0$,228. Rentang dari BootLLCI dan BootULCI juga tidak sampai nol (0). Kedua hasil ini menunjukkan bahwa peran mediator dari penyesuaian diri adalah sebagai mediator parsial. Dengan demikian penyesuaian diri memediasi pengaruh religiositas terhadap kebahagiaan secara parsial.

\section{PEMBAHASAN}

Penelitian ini bertujuan untuk menguji apakah penyesuaian diri memiliki peran sebagai mediator dalam pengaruh religiositas terhadap kebahagiaan santri di pondok pesantren. Hasil penelitian ini menemukan bahwa religiositas dapat mempengaruhi kebahagiaan santri, penyesuaian diri memiliki pengaruh terhadap kebahagiaan santri, dan penyesuaian diri menjadi mediator pengaruh religiositas terhadap kebahagiaan santri. 
Hasil penelitian ini mendukung teori dan hasil-hasil penelitian bahwa religiositas mempengaruhi kebahagiaan secara langsung maupun melalui mediator penyesuaian diri. Hasil penelitian mendukung hasil riset Rusman (2019) yang menyatakan pengaruh dari religiositas terhadap kebahagiaan bisa berjalan secara tidak langsung dengan dimediasi oleh kemampuan individu untuk beradaptasi dengan kejadiankejadian dalam hidupnya. Wulff (Baroun, 2006) menyatakan bahwa religiositas memiliki hubungan yang positif dengan kepuasan hidup, penyesuaian diri, kontrol diri, self-esteem, kebahagiaan, kesehatan fisik dan mental. Hasil analisis bootsrap dari pengaruh tidak langsung religiositas terhadap kebahagiaan menunjukkan bahwa rentang nilai BootLLCI dan BootULCI tidak sampai 0 sehingga dapat diketahui bahwa penyesuaian diri memediasi pengaruh religiositas terhadap kebahagiaan secara parsial.

Hasil penelitian ini mendukung hasil-hasil penelitian sebelumnya terkait pengaruh religiositas terhadap penyesuaian diri. Berbagai hasil penelitian sebelumnya menunjukkan bahwa pengaruh religiositas terhadap penyesuaian diri bersifat signifikan. Hal ini sejalan dengan penemuan-penemuan sebelumnya (Lesatari \& Indrawati, 2017; Nadzir \& Wulandari, 2013; Qomariyah, 2019). Lesatari dan Indrawati (2017) mengatakan bahwa santri yang memiliki religiositas yang tinggi akan memiliki penyesuaian diri yang baik. Dengan demikian hipotesis pertama penelitian ini diterima.

$\begin{array}{lcr}\text { Hasil } & \text { penelitian ini juga } \\ \text { mendukung } & \text { hasil-hasil penelitian } \\ \text { sebelumnya terkait religiositas memiliki }\end{array}$

pengaruh langsung yang signifikan terhadap kebahagiaan. Penemuan ini memperkuat pernyataan Eddington dan Shuman (2005) yang menyatakan bahwa agama dapat mempengaruhi kebahagiaan seseorang, dikarenakan agama dapat memberikan perasaan memiliki makna dan tujuan (Pollner, dalam Eddington \& Shuman, 2005) dan juga dapat memenuhi kebutuhan sosial individu melalui hubungan dan dukungan sosial dengan orang-orang yang memiliki kepercayaan yang sama (Gebauer, Sedikides, \& Neberich, 2012; Francis, Ziebertz, \& Lewis, 2003). Dengan demikian hipotesis kedua penelitian ini diterima.

Hasil penelitian ini juga mendukung hasil-hasil temuan sebelumnya terkait pengaruh penyesuaian diri terhadap kebahagiaan. Hasil-hasill penelitian sebelumnya yang menyatakan bahwa penyesuaian diri mempengaruhi kebahagiaan seseorang (Bazradshan dkk, 2018). Dengan demikian hipotesis penelitian ini diterima.

Kelemahan dalam penelitian ini adalah nilai reliabilitas yang rendah pada salah satu faktor dari skala kebahagiaan, di mana pada faktor ketiga yang terdiri dari 3 aitem hanya memiliki nilai alpha Cronbach sebesar $0,387 \quad(<0.5)$, yang menunjukkan bahwa faktor ini tidak reliabel. Menurut Pallant (2016), nilai alpha Cronbach sangat sensitif dengan jumlah aitem. Aitem yang sedikit (di bawah 10) dapat menghasilkan nilai alpha yang kecil, atau kurang dari 0.5. Apabila nilai alpha lebih rendah dari 0.5 , maka bisa dilihat pada nilai mean inter-aitem correlation (Pallant, 2016). Briggs dan Cheek (Pallant, 2016) merekomendasikan rentang inter-aitem correlation sebesar 0,2 $-0,4$ untuk hasil yang optimal. Pada ketiga 
aitem ini nilai rata-rata dari inter-aitem correlation dengan rentang 0,096-0,2,84. Nilai ini menunjukkan bahwa korelasi antar aitem pada faktor ketiga kebahagiaan ini rendah. Ketiga aitem ini berasal dari aspek joy dan self control. Adanya penggabungan variabel dalam sebuah faktor dikarenakan adanya sekumpulan variabel yang memiliki hubungan kuat dalam satu faktor, dan tidak memiliki korelasi dengan faktor lain (Usman \& Sobari, 2013). Dikarenakan skala ini merupakan skala yang diadaptasi dari bahasa asing, perbedaan budaya dan bahasa dapat menjadi salah satu alasan rendahnya reliabilitas pada faktor ini. Dengan demikian peneliti selanjutnya dapat menguji kembali alat ukur ini dengan melakukan penyesuaian pada aitem-aitem ini agar lebih dapat dipahami oleh siswa di Indonesia.

\section{PENUTUP}

\section{Kesimpulan}

Hasil penelitian ini menunjukkan bahwa penyesuaian diri memiliki peran sebagai mediator dari pengaruh religiositas terhadap kebahagiaan santri di pondok pesantren. Religiositas juga memiliki pengaruh langsung terhadap penyesuaian diri dan kebahagiaan santri. Artinya semakin tinggi religiositas yang dimiliki oleh santri maka semakin baik penyesuaian dirinya dan juga perasaan bahagianya selama di pesantren. Dengan demikian hipotesis penelitian diterima.

Hasil dari penelitian ini dapat menjadi acuan bagi pihak pondok pesantren untuk membantu santri baru menyesuaikan diri dan meningkatkan kebahagiaannya selama di pesantren, dengan meningkatkan ibadahnya dan kelekatannya dengan Allah.

\section{Saran}

Saran untuk peneliti selanjutnya yaitu: (a) peneliti selanjutnya yang tertarik dan ingin melakukan penelitian yang sama perlu mempertimbangkan jumlah aitem dari alat ukur yang digunakan, karena jumlah aitem yang terlalu banyak membuat partisipan jenuh dan tidak bersemangat dalam menyelesaikan kuisioner sepenuhnya; (b) peneliti selanjutnya dapat memperluas jenis partisipan dalam penelitian, seperti gender juga usia, dikarenakan dalam penelitian ini partisipan yang digunakanan hanya dari santri laki-laki maka hasil dari penelitian ini kurang dapat dilakukan generalisasi; (c) peneliti selanjutnya juga dapat membandingkan antara siswa yang sekolah di pesantren dan siswa yang tinggal di asrama namun tidak sekolah di pesantren, untuk membandingkan tingkat religiositas dari keduanya. 


\section{DAFTAR REFERENSI}

Abdel-Khalek, A. M. (2019). Religiousity and Well-Being. Encyclopedia of Personality and Individual Differences. Cham: Springer. https://doi.org/10.1007/9783-319-28099-8_2335-1

Abu-Raiya, H., Pargament, K. I., Mahoney, A., \& Stein, C. (2008). A Psychological measure of islamic religiousness: Development and evidence for reliability and validity. The International Journal for the Psychology of Religion, 18, 291-315. https://doi.org/10.1080/1050861080222 9270

Adeline, N. (2017). Adaptasi Alat Ukur Oxford Happiness Questionnaire. Skripsi. Medan: Universitas Sumatera Utara.

Afidah, M. (2017). Pengaruh Self-Efficacy dan Dukungan Sosial terhadap Penyesuaian Diri Siswa Baru SMA NU 1 Model Di Pondok Pesantren Tanwirul Qulub Sungelebak, Karanggeneng Lamongan. Skripsi. Malang: Univeristas Islam Negeri Maulana Malik Ibrahim.

Ancok, D., \& Suroso, F. A. (1994). Psikologi Islami: Solusi Islam Atas ProblemProblem Psikologi. Yogyakarta: Pustaka Pelajar.

Argyle, M., \& Crossland, J. (1987). The dimensions of positive emotions. British Journal of Social Psychology, 127137.

https://psycnet.apa.org/doi/10.1111/j.2 044-8309.1987.tb00773.x

Arif, I. S. (2018). Psikologi Positif: Pendekatan Saintifik Menuju Kebahagiaan. Jakarta: Pt Gramedia Pustaka.

Baker, R. W., \& Siryk, B. (1989). Student Adaptation to College Questionnaire Manual. Los Angeles: Western Psychological Services.

Baron, R. M., \& Kenny, D. A. (1986). The moderator-mediator variable distinction in social psychological research: Conceptual, strategic, and statistical considerations. Journal of Personality and Social Psychology, 11731182.

https://doi.apa.org/doi/10.1037/00223514.51.6.1173

Baroun, K. A. (2006). Relations among religiosity, health, happiness, and anxiety for Kuwaity adolescents. Psychological Reports, 99, 717-722. https://doi.org/10.2466/pr0.99.3.717722

Bazradshan, M. R., Abdi, A., Masmouei, B., Kavi, E., Abshorshori, N., Akbari, L., . . . Zakeri, M. (2018). The relation of social happiness and adjustment with vadalistic behavior of the children and young adults in the families under supervision of welfare office. Journal of Clinical and Diagnostic Research, 12 (8), 05-09.

https://doi.org/10.7860/Jcdr/2018/3518 4.11916

Cleveland, R. E., \& Sink, C. A. (2018). Student happiness, school climate, and school improvement plans: Implications for school counseling practice. Professional School Counseling. 21 (1), 1-10. https://doi.org/10.1177\%2F2156759X18 761898

Eddington, N., \& Shuman, R. (2005). Subjective Well-Being (Happiness). San Diego: Continuing Psychology Education. https://www.texcpe.com/html/pdf/ca/ ca-happiness.pdf

Francis, L. J., Ziebertz, H.-G., \& Lewis, C. A. (2003). The relationship between religion and happiness among German students. Pastoral Psychology, 51 (4), 273-281. DOI: 10.1023/A:1022529231234

Gebauer, J. E., Sedikides, C., \& Neberich, W. (2012). Religiosity, social self-esteem, and psychological adjustment: On the cross-cultural specificity of the psychological benefits of religiosity. Psychological Sciece, 23 (2), 158-160. 
https://doi.org/10.1177\%2F0956797611 427045

Graham, J., \& Haidt, J. (2010). Beyond belief: Religions bind individual into moral community. Personality and Social Psyhology Review, 14 (1), 140-150. https://doi.org/10.1177\%2F1088868309 353415

Grama, B. (2018). The student adaptation to college questionnaire (SACQ) for use with Romanian students. Psihologia Resurseor Umane Revista Asociatiei de Psihologie Indusstriala si Organizationala, 16 (1), 16-26. https://psycnet.apa.org/doi/10.1037/t0 6525-000

Hayes, R; Sabapathy, K; Fidler, S (2011) Universal Testing and Treatment as an HIV Prevention Strategy: Research Questions and Methods. Current HIV research, 9 (6). pp. 429-45. ISSN 1570$162 X$

Hossain, M. Z., \& Rizvi, M. A. (2017). Relationship between religious belief and happiness in Oman: a statistical analysis. Mental Health, Religion $\mathcal{E}$ Culture, 781-790. https://doi.org/10.1007/s10943-0160332-6

Hurlock, E. B. (2002). Psikologi Perkembangan: Suatu Pendekatan Sepanjang Rentang Kehidupan. Jakarta: Penerbit Erlangga.

Joodat, A. S., \& Zarbakhsh, M. (2015). Adaptation to college and interpersonal forgiveness and the happiness among the university students. Practice in Clinical Psychology, 3 (4), 243-250.

http://applications.emro.who.int/ime mrf/J_Pract_Clin_Psychol/J_Pract_Cli n_Psychol_2015_3_4_243_250.pdf

Lesatari, D., \& Indrawati, E. S. (2017). Hubungan antara religiusitas dengan penyesuaian diri pada siswa dan siswi kelas VII Yayasan Pondok Pesantren Futuhiyyah Mraggen Kabupaten
Demak. Jurnal Empati, 6 (04), 307-312. https://ejournal3.undip.ac.id/index.ph p/empati/article/download/20098/189 68

Mahudin, N. D., Noor, N. M., Dzulkifli, M. A., \& Janon, N. S. (2016). Religiosity among muslims: A scale development and validation study. Makara HubsAsia, $\quad 20 \quad$ (2), 109-120. https://doi.org/10.7454/mssh.v20i2.349 $\underline{2}$

Mundzir, M. F. (2014). Religiusitas dan Kebahagiaan Pada Santri Pondok Pesantren.Skripsi. Yogyakarta: Universitas Islam Negeri Sunan Kalijaga.

Nadzir, A. I., \& Wulandari, N. W. (2013). Hubungan religiusitas dengan penyeusaian diri siswa pondok pesantren. Jurnal Psikologi Tabularasa, 8 (02), 698-707. http://jurnal.unmer.ac.id/index.php/jp t/article/view/213/84

Nashori, F. (2011). Kekuatan karakter santri. Millah, 11 (1), 203-219. https://journal.uii.ac.id/Millah/article/ view/5092/4501

Pallant, J. (2016). SPSS Surviving Manual: A Step by Step Guide to Data Analysis Using IBM SPSS (6th Edition). New York: McGraw Hill Education.

Pritaningrum, M., \& Hendriani, W. (2013). Penyesuaian diri remaja yang tinggal di Pondok Pesantren Modern Nurul Izzah Gresik pada tahun pertama. Jurnal Psikologi Kepribadian dan Sosial, 02

141-150.

http://journal.unair.ac.id/filerPDF/jpks 417dbf33fb2full.pdf

Qomariyah, S. (2019). Hubungan Religiusitas dengan Penyesuaian diri pada satriwati di pondok pesantren mahasiswi Al-Husna Jember. Skripsi. Jember: Universitas Jember.

Rahma, A. (2016). Hubungan Antara Penyesuaian Diri dengan Kemandian belajar siswa kelas X SMA Exceller Al- 
Yasini yang Tinggal di Pondok Pesantren. Skripsi. Malang: Universitas Islam Indonesia Maulana Malik Ibrahim.

Rahmawati, W., Saragih, J. I., \& Adeline, N. (2016). Psychometric properties of Indonesian version of the Oxford Happiness Questionnaire. Advances in Health Science Research, 5(1), 229-232.

Roessler, J., \& Gloor, P. A. (2020). Measuring happiness increases happiness. Journal of Computational Social Science, 1-25. DOI: 10.1007/s42001-020-00069-6

Rusman A. A. (2019). Relationship Between Religiosity and Happiness: The Mediationg Role of
Self Control, Self-Regulation, and Life Satisfaction. Disertasi. Pulau Penang: Universiti Sains Malaysia Salsabila, D.F., Rofifah, R., Natanael, Y. \& Ramdani, Z. (2019). Uji Validitas Konstruk IndonesianPsychological Measurement of Islamic Religiousness (I-PMIR). Jurnal Psikologi Islam dan Budaya, 2(2), 77-86.

Usman, H., \& Sobari, N. (2013). Aplikasi Teknik Multivariate. Jakarta: Rajawali Press 